\title{
O TEMA DA VERDADE EM FOE, DE J. M. COETZEE
}

\author{
Fernando de Lima Paulo*
}

RESUMO:

Este ensaio pretende estabelecer que Foe, de J. M. Coetzee, ao rejeitar o culto do relativismo fácil, executa um movimento além do ceticismo das práticas ficcionais marcadamente pósmodernas, e elabora estratégias vislumbrando uma posição diferente, na qual a idéia da verdade é examinada.

PALAVRAS-CHAVE: África do Sul, ficção, pós-modernismo.

John Michael Coetzee é um escritor sul-africano ainda pouco conhecido do público leitor brasileiro, mesmo daquele cujo ofício se relaciona à leitura de livros, a saber, os críticos literários ou mesmo a Academia. Por estas plagas, ganhou alguma notoriedade ao receber duas vezes o prestigiado prêmio literário inglês Booker Prize por seu quarto romance, The Lives and Times of Michael $K$, e por seu último livro, Disgrace, traduzido ao português como Desonra. Traz em seu currículo oito romances ganhadores de prêmios literários importantes, além de trabalhos críticos e de lingüística, uma outra preocupação intelectual sua, sem falar da matemática e das ciências da computação, disciplinas nas quais se bacharelou e obteve por algum tempo seu ganha-pão. Aposentou-se recentemente da cátedra de professor de literatura da Universidade da Cidade do Cabo, mas, apesar do reconhecimento crescente, continua arredio à imprensa. Para os mais curiosos, uma boa oportunidade de conhecer o homem por trás dos livros é a coletânea de entrevistas e ensaios Doubling the Point: Essays and Interviews, editada por David Atwel1, infelizmente ainda sem tradução.

Certamente ao sabor crítico pós-moderno, que possui uma especial predileção por escritores cujos textos voltam-se sobre si mesmos de modo a oferecer uma investigação sobre a linguagem como sistema, e sobre a impossibilidade desta em representar a verdade, o absoluto, os textos de J. M. Coetzee revelam-se instigantes.

| Mestre em Letras: Estudos Literários (Área de concentração: Literaturas de Expressão Inglesa), 2002. 


\section{EMTESE}

Belo Horizonte, v. 7, p. I-I I0, dez. 2003

Não somente por serem textos que se debruçam sobre o "medium" no qual se constroem, mas também por sua dimensão cerebral e ao mesmo tempo ética, o que traz a eles a reputação (justa) de políticos ou (injusta, a meu ver) de bizantinos. Sem dúvida, por sua prosa asséptica de humor e ironia, não facilmente digerivel, na qual o autor parece reescrever à exaustão cada frase, aparando arestas, tirando excessos; uma prosa que parecer minar, ao longo de sua construção, a própria razão de ser; uma prosa que se percebe em guarda contra si mesma, que expõe as dificuldades atinentes ao uso da linguagem, mas que, longe de perder-se na contemplação do próprio umbigo, dirige-se também a temas caros à existência humana, essa existência excruciada pelo peso da história. A verdade ante a impossibilidade de sua representação, a justiça ante a impotência por sua não concretização, o sofrimento ante a banalidade da violência transformam o texto coetzeeano em algo, além de extremamente lúcido acerca do ato de escrever, não conformista em relação a essa visão pós-moderna mais "ortodoxa," irônica e descrente das visões humanistas suscitadas por preocupações éticas. Assim, por sua difícil caracterização, Coetzee figura-se, para alguns, "o mais esquivo dos escritores, cujas ficções parecem quase deliberadamente construídas para escapar qualquer tipo de interpretação", e cuja "obra [é] ao mesmo tempo realista e subversiva da estética realista; na qual a violência policial e pósmodernismo convivem lado a lado; na qual a África do Sul, sua terra natal, aparece ao mesmo tempo central e marginal às suas preocupações" (Huggan e Watson 1996: 1).

Este ensaio centra-se em um dos seus livros, Foe (1986), uma reescritura do famoso Robinson Crusoé de Daniel Defoe, um dos textos fundadores do romance moderno. Foe tem sido analisado amiúde como um exemplo de metaficção pós-moderna ou pós-colonial. A primeira, como já dito, um texto que se debruça sobre si mesmo e desfaz-se das pretensões de revelar a verdade; a segunda, uma postura política, subversiva ao cânone europeu. Sem debater exaustivamente as características do romance que ratificariam ou divergiriam de uma ou de outra escola de pensamento, minha idéia prende-se somente à discussão da verdade num ambiente intelectual marcado por um profundo ceticismo, como o é o pós-modernismo, e que tipo de abordagem ética essa tentativa ficcional pode fornecer como discurso quando, ao expôr os artifícios de sua própria construção, o texto explora ao máximo a ficção como discurso, criando estratégias que põem em xeque seu próprio ceticismo. 
Foe divide-se em quatro partes. Com uma série de cartas ao escritor Foe ${ }^{1}$ (uma clara referência metaficcional a Daniel Defoe), o romance começa com o relato de Susan Barton e de sua experiência de náufraga. Depois de ter viajado à Bahia, Brasil, e procurado em vão por sua filha raptada, Susan tenta retornar à Inglaterra num navio mercante, que é tomado por um motim. 0 capitão do barco, de quem Susan havia se tornado amante, é morto, ela é posta num bote com o cadáver e deixada à deriva perto de uma ilha supostamente deserta. Após remar exaustivamente, chega à praia, sendo resgatada por um "Negro com uma cabeça de lã bem enrolada, nu salvo pelas bermudas de tecido rústico" (1986: 5-6). Descobre depois que este, de nome Sexta-Feira, tem um senhor, Robinson Cruso² $^{2}$, e que sua língua fora cortada; se por piratas ou pelo próprio Cruso, não sabe ao certo. A primeira parte resume-se às impressões de Susan: a estranheza que o lugar provoca, a falta de empreendedorismo por parte de Cruso, a sua relutância em ser resgatado, em registrar suas experiências num diário e ainda o estranho uso da linguagem de que fazem entre si ele e Sexta-Feira.

0 que se nota nessa primeira parte é o desejo de Susan em oferecer seu relato como expressão da verdade, afinal, se não puder fazê-10, se, como diz, "não puder assegurar a verdade da minha história, de que valerá?" (40). Desta forma, diante da proposta do capitão do barco, que a aconselha a procurar um escritor para tornar sua história vendável, rebate-a com firmeza, pois "não admiti[rá] mentiras." No entanto, ao declarar seu compromisso com a verdade, Susan parece entrar em conflito com o discurso que adota. Sendo uma narradora e, numa análise mais feminista do texto, haveria nisso uma crítica à voz do homem branco europeu presente em Robinson Crusoé, seu discurso revela um lado também eurocêntrico. Na verdade, Susan parece recorrer às tradicionais narrativas de exploradores. Ela descreve os costumes alimentares de Cruso e Sexta-Feira (9), suas ferramentas (15), o relevo e clima da i1ha (7), etc. Parece haver uma aversão à diferença, às coisas a que o explorador não está habituado e sua tendência natural de vê-las como sujas ou impróprias. Numa descrição olfativa da ilha e de seus habitantes, Susan descreve: "perto da ilha, havia algas pardas, que, trazidas pela maré, exalavam um cheiro desagradável" (7); a cabana de Cruso cheirava a "curtume" (6); Sexta-Feira recendia a "peixe e lã de carneiro num dia quente" (6). Critica também a indolência, já que, para ela, "Cruso não toleraria nenhuma transformação em sua ilha" (27). Considera-o, portanto, um indivíduo apático que passa longas horas absorto na contemplação do mar ou no trabalho sem propósito 


\section{EM TESE}

Belo Horizonte, v. 7, p. I-I I0, dez. 2003

de seus terraços, espaços abertos por ele à agricultura, para os quais, ironicamente, Cruso não possui sementes para cultivar.

Se há em Coetzee a vontade de oferecer uma subversão ao cânone ao optar por uma voz feminina em oposição ao discurso masculino de Robinson Crusoé e assim desconstruí-10, pode-se notar, no entanto, um descompasso entre o relato de Susan e o material que the serve à narrativa, fazendo com que essa interpretação seja vulnerável. Por exemplo, se Susan acusa Cruso e Sexta-Feira de indolência, caberia então questionar a que atividade os dois se dedicam quando não estão sem fazer nada. Através de Susan, sabe-se que Cruso não queria estabelecer uma colônia ou melhorar sua condição material, mas não the faltam habilidades manuais. Susan diz-nos, por exemplo, que a cabana de Cruso fora construída com estacas e cipós "entrelaçados engenhosamente" (9), também que seu forno fora "moldado na pedra com grande habilidade" (14). Sexta-Feira demonstra também perícia na pesca: "Como ele podia arpoar um peixe com o ventre apoiado num tronco de madeira não era claro para mim" (31), espanta-se ela.

Outro exemplo que denuncia a narrativa situa-se no âmbito das relações de poder. Ao chegar à ilha, Susan diz que havia se tornado "o segundo súdito" de Cruso, "o primeiro sendo seu servo Sexta-Feira" (11). Cruso seria, assim, "o verdadeiro monarca de sua $i 1 h a "$. Susan observa, porém, que "na verdade a ilha não pertencia mais a Cruso que ao rei de Portugal ou mesmo a Sexta-feira ou aos canibais da África" (26). Duvida, mais à frente, sobre sua real posição em relação a Cruso, se de "irmão e irmã, hospedeiro e convidada, senhor e serva, ou o que quer que eles fossem" (30). A autoridade de Susan como narradora perde-se num processo de auto-engano, posto que a verdade que nos quer mostrar cambaleia ante às inúmeras leituras possíveis de seu texto.

Em uma de suas entrevistas, J. M. Coetzee assinala, no entanto, que "para Susan Barton, a questão que se põe é somente uma: o livro não é de Foe, é dela, mesmo que na condição de indicativo de sua procura por um inimigo [Foe ${ }^{3}$ que a conte por ela" (Coetzee 1992: 248). Do autor, de certa forma, tem-se então um apoio à autoridade de Susan, mesmo em face aos desacertos de suas narrativa. Essa postura não ilumina, mas levanta outros questionamentos: haveria uma intencionalidade de Coetzee em utilizar-se de uma personagem feminina para subverter o processo de silenciamento presente em Robinson Crusoé, no qual a voz feminina é completamente suprimida, por que o discurso em questão pode ser lido como eurocêntrico? Seria uma 
subversão dessa leitura? Nesse caso, por que o desejo de Coetzee em assegurar autoridade de sua personagem e afirmar que a história the pertence? Seria Susan Barton então a representação de uma personagem que se engana ao tentar representar a verdade? 0 que se pode dizer, talvez, é que há pelo menos um conflito entre desejo e discurso, que se exacerba nas duas partes seguintes, resultando num processo de hiperconsciência, no qual uma verdade apreendida pelo auto-exame de Susan vem acompanhada de um oposto, ou seja, por trás de cada máscara de verdade existe uma outra, que jamais será a última, a definitiva.

Na parte II, já na Inglaterra, Susan contrata os serviços do sr. Foe, "um autor que ouviu muitas confissões" (48). No entanto, Foe, levado por dívidas, foge sem completar sua tarefa. Susan muda-se com Sexta-Feira para sua casa abandonada e, sem receber notícias de seu paradeiro, desanima-se. Resolve ela própria escrever sua história, mas, apesar dos esboços iniciais, depara-se com um grande problema: sua narrativa torna-se impraticável sem o conhecimento do que aconteceu a Sexta-Feira, a história de sua mutilação. Para isso, tenta de todos os modos estabelecer alguma forma de comunicação com ele, quer através do ensino da fala, quer da escrita ou da música, todas enfim provam-se tentativas frustradas: Sexta-Feira mostra-se indiferente, ensimesmado. Nesse interim, aparece uma moça dizendo-se a filha raptada de Susan, de mesmo nome, que estava à sua procura. Susan não a reconhece e desconfia de que não passa de uma interferência de Foe em sua história. Desesperada, tenta levar Sextafeira de volta à África, desistindo no final por temer que este retornasse ao cativeiro. Na parte III, Susan descobre o esconderijo de Foe e, com Sexta-Feira a reboque, vai ao seu encontro, insistindo que ele escreva sua história de forma verídica. Ela não quer nada de piratas, canibais, ou mesmo da sua estada na Bahia; quer a verdade, os fatos. Foe, porém, tem outra idéia em mente, uma história com começo, meio e fim, que teria a ilha não como centro, mas um episódio na história de uma mãe à procura de sua filha raptada.

Sem dúvida, as partes II e III do romance podem ser vistas como evidência da impraticabilidade do discurso histórico como verdade. Por outro lado, se Robinson Crusoé, ao ser analisado como tentativa nesse sentido, promove distorções e o silenciamento de outras verdades, Susan, ao insistir num relato factual, que inclua a história da mutilação de Sexta-Feira e, portanto, reflita seu desejo de autoria, 


\section{EMTESE}

Belo Horizonte, v. 7, p. I-I I0, dez. 2003

caminha, por assim dizer, para um impasse: como dizer a verdade para si e sobre si mesma sem cair no auto-engano? Uma representação fiel da realidade, bem ao sabor de uma narrativa histórica é, sem dúvida, uma prática que jamais vai calar as digressões possíveis e infinitas, já que, por trás de uma verdade exposta, ocorre sempre um silêncio intangível, irrepresentável, mas sempre presente, subversivo. Em Foe, Sexta-Feira representa esse mistério de maneira hábil. Susan tenta partilhar sua experiência de náufraga e, em seu relato, dar-se conta desse enigma, ou melhor, desse "buraco narrativo", essa história que "tão teimosamente mantém seu silêncio. A sombra", como explica Foe, "cuja falta [Susan] sente estar lá: é a perda da língua de Sexta-Feira" (117).

Como foi dito, se o olhar crítico contemporâneo recai sobre as vozes silenciadas ou distorcidas em Robinson Crusoé, que conta a história sob o ponto de vista do colonizador - o Sexta-Feira de Defoe certamente não é mudo, mas nunca fala o inglês correto de seu amo; as mulheres são relegadas a um espaço marginal ou inexistente - Foe, como uma revisão, leva então a cabo a subversão de um texto canônico (aqui visto como fundador, superior, paradigma), desarticulando-o de dentro para fora ao mostrar que sua pretensão de verdade cai por terra ao ser posta em contraste com a realidade da mulher expropriada e do indígena emudecido.

Essa leitura é possível e bem ao gosto pós-moderno. Mas há senões. Como alvo dessa crítica, Robinson Crusoé, a um correr d'olhos, mostra-se, porém, sinuoso. Segundo Coetzee, o romance nem é o melhor texto de Defoe; apresenta "uma composição apressada e uma falta de revisão", "sua moral é confusa", "a última parte do livro, bem como as primeiras aventuras de Crusoé, poderiam ter sido melhor elaboradas por qualquer escritor mais hábil" (Defoe 1999: viii). No entanto, nas mãos de Defoe, Robinson Crusoé transformou-se nos três séculos seguintes à sua publicação "provavelmente na cristalização mais forte da cultura ocidental no que diz respeito à sobrevivência do indivíduo, aos fundamentos da civilização e na dialética do explorador-explorado" (1996: 170). Como nos diz Linda Hutcheon, "as obras de Defoe pretendiam-se verídicas e, na verdade, convenceram alguns leitores de sua factualidade, porém a maioria dos leitores atualmente (e de muitos na época) desfruta o prazer dessa dupla consciência da ficcionalidade e da base no 'real' do texto, como o fazem os leitores da metaficção historiográfica contemporânea" (Hutcheon 1989: 107), ou seja, o texto pós-moderno por 
excelência, segundo a autora. Coetzee é mais incisivo sobre as habilidades de Defoe como escritor: "Defoe é na verdade algo bem mais simples: um imitador, um ventríloquo, um falsificador" (1999: vii). Isso é confirmado no prefácio de seu livro, em que Defoe escreve como o próprio Robinson: "0 Editor crê ser tudo um relato de fatos; nada há nele de qualquer semelhança à ficção" (1999: 3), e nas diversas obras sobre os mais diversos e inusitados assuntos.

Em conseqüência, Daniel Defoe está longe de estabelecer-se como o "autor", aquela função do discurso que, no dizer de Foucault, representa um "modo no qual o texto remete a essa 'figura' que, pelo menos na aparência, the é exterior e o antecede" (Foucault 1991: 110). Se Foe pretende-se uma paródia do texto de Defoe, qual é, então, sua eficiência subversiva se Robinson Crusoé pode ser visto como uma farsa, burlando os limites entre a realidade e ficção e, a seu modo, questiona também a própria noção de verdade?

Mas Foe não se perde no embate entre o desejo de Susan e o ceticismo de Foe. A parte final do romance reserva-nos surpresas e, segundo Coetzee, "encara de frente o interminável ceticismo" (1996: 248) dos capítulos anteriores. Um narrador desconhecido intromete-se na história. Numa descrição quase onírica, após duas tentativas fracassadas, ele se encontra no que parece ser o esconderijo de Foe e depara-se com corpos aparentemente mumificados, "que pesam menos que um saco de palha" (1986: 153), o narrador mergulha no mar em direção a Sexta-Feira, que jaz no naufrágio "com a corrente em volta do pescoço" (157). Ao aproximar-se, pressiona seu dedo contra os dentes de Sexta-Feira para abrir-1he a boca. De lá saem os sons da i1ha. São sons, e não representações do que possa ser a verdade, já que este lugar não é o lugar de palavras, mas o lugar onde "os corpos são seus próprios sinais" (157).

Para essa última parte, Coetzee não apresenta algo que se esquiva de ser um final, indicando, se assim o fizesse, que a discussão engendrada por Susan continuaria indefinidamente, mas também não anuncia a verdade de Sexta-Feira, não revela o que ela é. No entanto, Sexta-Feira é presença asfixiante no texto, é corpo e não desaparece; o corpo, segundo Coetzee, "com seu sofrimento opõe-se às inquietações intermináveis da dúvida. [...] Seu poder é inegáve1" (1996: 148). No caso de SextaFeira, as marcas de seu sofrimento são indeléveis: a língua arrancada, a suposta emasculação, a cicatriz da corrente no pescoço remetem a uma violência brutal, e essa visão de horror investe o corpo em sofrimento de sua autoridade. 


\section{EM TESE}

Belo Horizonte, v. 7, p. I-I I0, dez. 2003

NOTAS:

1. Sabe-se que a partícula "De" de Defoe fora introduzida por questões comerciais para dar uma ascendência flamenga ao escritor, nunca confirmada; seu sobrenome era Foe.

2. Segundos alguns críticos, o "Crusoe" de Defoe teve por origem o sobrenome de um pastor puritano amigo seu, Timothy Cruso (Attwel1 1993: 107). 0 interessante é que Coetzee reverte à grafia original.

3. "Foe", além do sobrenome do autor de Robinson Crusoé, em inglês significa também inimigo, adversário, antagonista, desafeto.

ABSTRACT :

This essay intends to establish that J. M. Coetzee's Foe, by declining the cult of mere relativism, stages a move beyond the scepticism in fictional practices markedly postmodern, as it works out strategies looking for a different position in which the idea of truth is examined, and an ethical position is staged.

KEY WORDS: South Africa, fiction, postmodernism.

REFERÊNCIAS BIBLIOGRÁFICAS

Attwe11, David. South Africa and the Politics of Writing. Berkeley: University of California Press, 1993.

Coetzee, J. M. Foe. London: Penguin Books, 1986.

Coetzee, J. M. Doubling the Point: Essays and Interviews. Ed. David Attwel1. Cambridge, MA; London: Harvard University Press, 1992.

Defoe, Daniel. The Life and Surprising Adventures of Robinson Crusoe of York, Mariner. 0xford: 0xford University Press, 1999.

Foucault, Michel. "What is an Author?" The Foucault Reader. Ed. e comp. Paul Rabinow. London: Penguin Books, 1991. p. 101-119.

Huggan, Graham, e Stephen Watson, eds. Critical Perspectives on J. M. Coetzee. London: Macmillan Press Ltd, 1996.

Hutcheon, Linda. The Politics of Postmodernism. London: Routledge, 1989. 